\title{
Registro de Protocolos Clínicos
}

P rezados leitores,

No número anterior da Revista Brasileira de Reumatologia (RBR), enfatizamos a relevância da realização de estudos observacionais para melhorar o nosso nível de informação sobre a realidade da epidemiologia e o quadro clínico das doenças de interesse do reumatologista em nossa região. Ao mesmo tempo, naquele texto, destacávamos a importância da publicação de Ensaios Clínicos Randomizados (ECR) como material científico considerado como apresentando maior pontuação, quando se tentam determinar critérios de relevância para estabelecer "verdades científicas".

Recentemente, recebemos correspondência endereçada à Editoria, estabelecendo critérios para a publicação de protocolos clínicos nos periódicos indexados às Bases de Dados Lilacs e e SciELO, como é o caso da RBR. Consoante com a nossa preocupação em seguir essa recomendação, estamos incluindo-a nas Instruções aos Autores, de sorte que todos os artigos que se refiram a protocolos clínicos iniciados a partir do corrente ano, independentemente de terem sido realizados a partir de iniciativa pública ou privada, somente serão aceitos se tiverem registro em um dos Registros de Ensaios Clínicos validados pela Organização Mundial da Saúde (OMS) e pelo International Committee of Medical Journal Editors (ICMJE). O número desse registro deverá ser mencionado na publicação, segundo explicitado nas instruções aos autores.

Por ser a RBR indexada em ambas as bases Lilacs e SciELO, não há dúvidas quanto à necessidade de adotarmos essa nova exigência. Entretanto, gostaríamos de deixar patente que, a despeito desse compromisso, a Editoria da $\mathrm{RBR}$, em sintonia com os princípios que prezam pelo rigor ético no aceite para publicação de artigos, vê essa iniciativa como mais um passo no incremento da transparência para a comunidade científica em relação aos resultados obtidos de ensaios clínicos. Essa transparência é fundamental para que pesquisadores, agências financiadoras de pesquisa, gestores da área de saúde, médicos, pacientes e o público em geral tenham acesso à informação sobre estudos clínicos em andamento, finalizados e publicados para guiar a sua tomada de decisão, garantindo que todos os resultados estejam disponíveis e aumentando a confiança da sociedade na maneira como as pesquisas clínicas são conduzidas.
A seguir, transcrevemos o texto que nos foi encaminhado, certos de que este representa mais um passo na melhoria do nível técnico de nossas publicações.

Francisco Airton Castro da Rocha

Doutor em Reumatologia, Professor Adjunto de Reumatologia, Faculdade de Medicina da Universidade Federal do Ceará (UFC)

Ricardo Machado Xavier Doutor em Imunologia, Universidade de Shimane, Japão, Professor Adjunto de Reumatologia, Universidade Federal do Rio Grande do Sul (UFRGS)

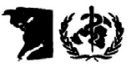

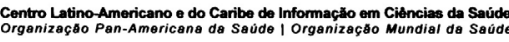

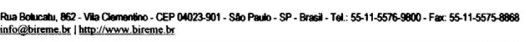

Recomendaçăo aos editores de revistas indexadas na LILACS e SciELO sobre Registro de Ensaios Clínicos 15 de maio de 2007

Comunicamos a todos os editores dos periódicos indexados nas bases de dados LILACS SciELO que, a partir de agosto de 2007, a BIREME passará a exigir que os periódicos que publicam ensaios controlados aleatórios (randomized controlled trials) e ensaios clinicos (clinical trials) incluam nas Instruçōes aos Autores a recomendação para o registro prévio dos ensaios publicados e passem a exigir o respectivo número de identificação como condiçăo para aceitação dos manuscritos.

Essa decisăo segue a orientação da Plataforma Internacional para Registros de Ensaios Clínicos (ICTRP) da Organizaçăo Mundial da Saúde - OMS, do Intemational Committee of Medical Joumal Editors, e do Workshop ICTPR: strategies to promote adherence to the Intemational Clinical Trials Registry platform in Latin America \& the Canibbean, realizado durante $\circ 8^{\circ}$ Congresso Brasileiro de Saúde Coletiva e $11^{\circ}$ Congresso Mundial de Saúde Pública, em 2006.

A OMS destaca a importância dos ensaios clínicos como fontes de evidência da eficácia e segurança das intervençőes em saúde e a necessidade do seu registro para assegurar transparência na sua realizaçăo e publicação dos resultados e dar cumprimento às responsabilidades éticas.

O texto sugerido aos editores para inclusão nas Instruçōes aos Autores é:

"O periódico XXX apóia as políticas para registro de ensaios clínicos da Organizaçáo Mundial da Saúde (OMS) e do International Committee of Medical Joumal Editors (ICMJE), reconhecendo a importåncia dessas iniciativas para o registro e divulgaçăo internacional de informação sobre estudos clinicos, em acesso aberto. Sendo assim, somente serão aceitos para publicação, a partir de 2007, os artigos de pesquisas clinicas que tenham recebido um número de identificaçăo em um dos Registros de Ensaios Clinicos validados pelos critérios número de identificaçăo em um dos Registros de Ensaios Clínicos validados pelos criterios
estabelecidos pela OMS e ICMJE, cujos endereços estão disponiveis no site do ICMJE. O número de identificaçăo deverá ser registrado ao final do resumo."

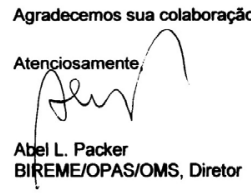

